\title{
FRAMING 'ASIA': RESULTS FROM A VISITOR STUDY AT THE RIJKSMUSEUM'S ASIAN PAVILION
}

What are the most popular exhibits in the Rijksmuseum's Asian Pavilion? How do visitors see the Asian Pavilion in relation to the main building? And how do visitors respond to the co-presentation of contemporary and historical pieces?

During a period of three consecutive days in April 2014, the authors of this article - with assistance from the participants of a Leiden University museum studies programme - conducted 200 face-to-face interviews based on a structured questionnaire in either Dutch or English, and 183 tracking studies during which visitors were followed on their path through the exhibition rooms. The qualitative empirical study was designed for generating hypotheses for further research; the results are not to be understood as representative or conclusive.

\section{Favourite Exhibits}

"The scary-looking two guys" [sic] are the most popular exhibits in the Asian Pavilion - when asked what exhibits they found most interesting or liked best, $40 \%$ of interviewed visitors indicated the two Japanese temple guardians (fig. 1). In describing the guardians as "warriors" or "wooden evil figures," for example, some visitors voiced their own visual and emotional perception of the sculptures.

Roughly a quarter of visitors mentioned the Shiva Nataraja statue describing it, for example, as "the big one with the beautiful arms." (fig. 2)

Almost a fifth of interviewees indicated the "Buddha" or "Buddha sculptures" as their favourite pieces. These included the sculpture of the Buddha disciple or lohan Ajita with its glass-inlayed eyes, described by one visitor as - "the Buddha with eyes, funny and cool."2

These findings were supported by tracking studies that traced visitors' itineraries and measured the time visitors spent in front of each exhibit. The results are visualised through a 'heat map' indicating both hot spots and dead spots (fig. 3). The most frequented red hot spot in the Asian Pavilion appeared in the lower section around the Japanese temple guardians, followed by the second most frequented spot, the Shiva Nataraja statue, on the ground floor. As the heat map indicates, visitors tended to pass alongside many of the displayed items without intensely engaging with the exhibits.

It is noticeable that the two most popular exhibits, the temple guardians and the Shiva Nataraja sculpture, were also the only exhibits in the Asian Pavilion mentioned on the Audio Guide. A quarter of the visitors indicated ${ }^{\text {Down }}$ access 
Fig. 1

View of the display in the lower section of the Asian Pavilion at the Rijksmuseum Amsterdam. In the background featuring Two Temple Guardians, wood with traces of colour, h. 237 cm., Japan, c. 1300 - c. 1400 , inv.nr. AK-RAK-2007-1-A.

Fig. 2

View of the display on the upper floor of the Asian Pavilion at the Rijksmuseum Amsterdam, in the middle featuring Shiva Nataraja, bronze, h. $153 \mathrm{~cm}$., India, 1100 - 1200, inv.nr. AK-MAK-187.
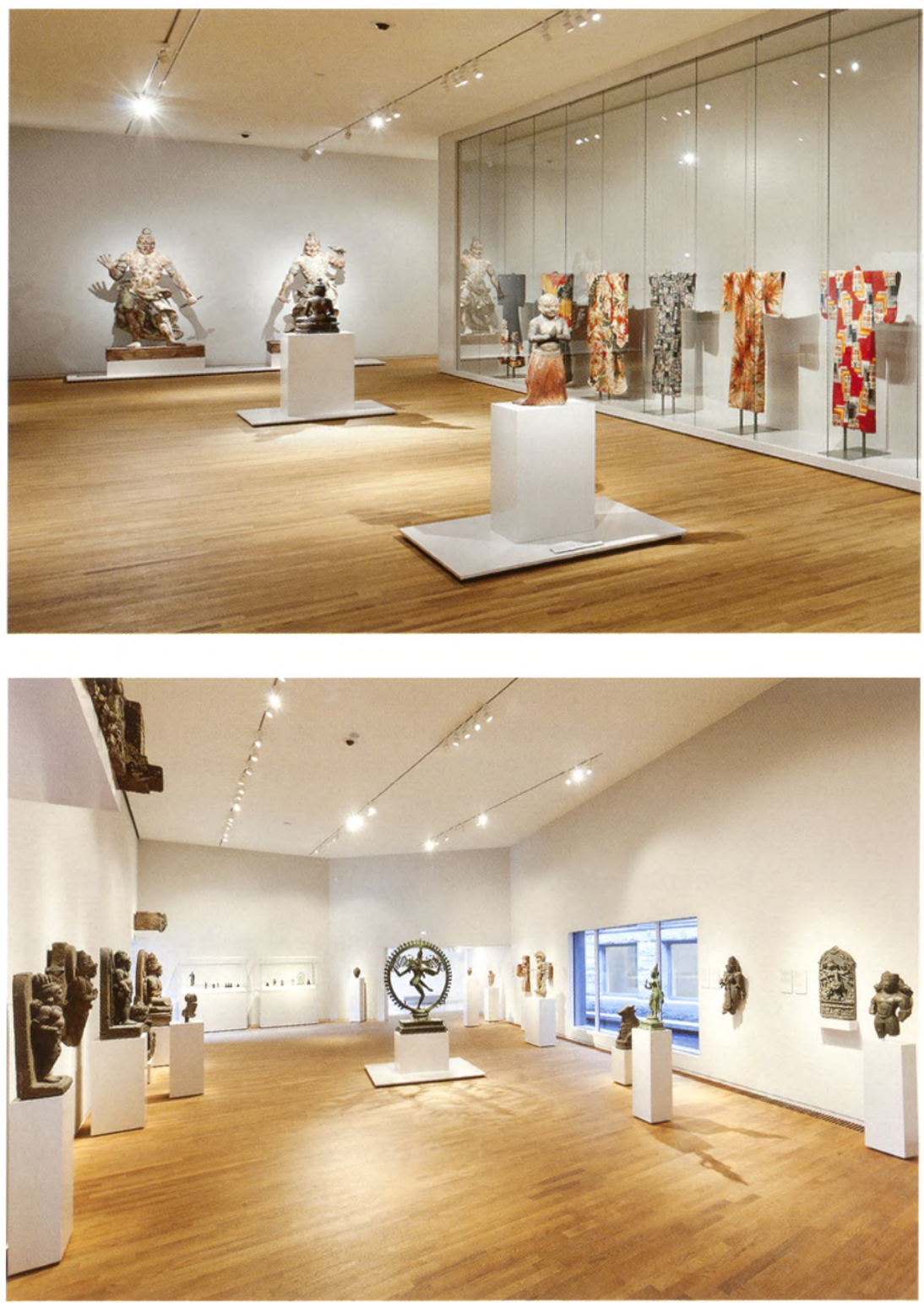

the Audio Guide as their main reason for visiting the Asian Pavilion, and a further $15 \%$ said they wanted to "finish the whole museum." While another quarter of visitors wandered in by chance, only $2 \%$ of visitors said that they had come to the museum specifically to visit the Pavilion.

\section{The Co-presentation of Contemporary and Historical Pieces}

The contemporary artworks by Ai Weiwei (fig. 4) and Edmund de Waal (fig. 5) were not frequented by many visitors. The findings from the interviews indicated that more than half of visitors (56\%) did not notice Ai's Tea Brick displayed as an isolated piece on the staircase, and almost three quarters (72\%) did not see Edmund de Waal's work placed in a transition area on the lower floor. 
Fig. 3a and $3 b$ Heat Map based on Visitor Tracking Studies conducted at the Asian Pavilion, Rijksmuseum Amsterdam.

(C) Annette Löseke.

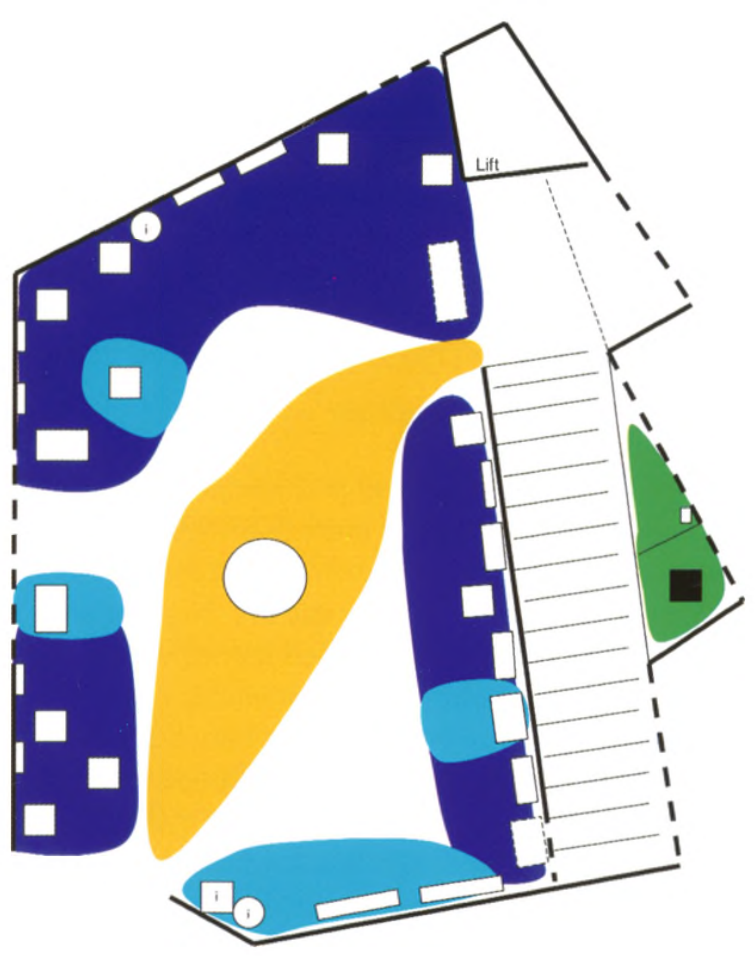

||||||||||||||||||||||||||||||||||||||||| |||||||||||||||||||||||||||||||||||||||||||||||

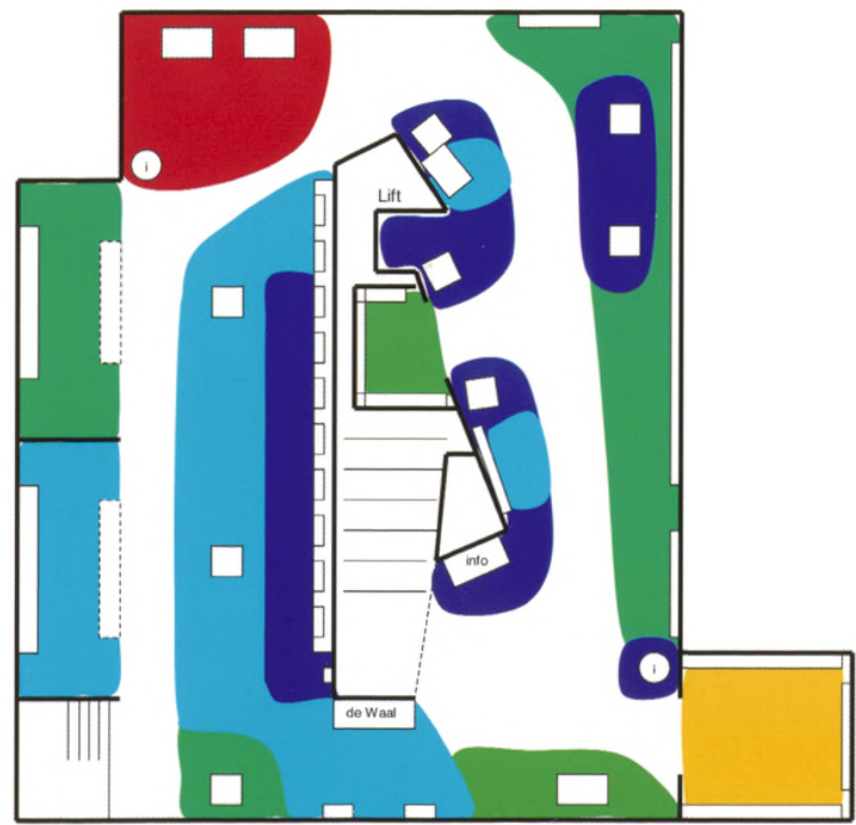

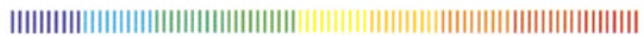


Visitors who had noticed the contemporary artworks either tended to see no relation between the contemporary and historical exhibits, or perceived the contemporary artworks as "different" from the historical pieces. Some visitors considered the pieces to be connected by (Asian) tea or, rather vaguely, by 'Asia'. Others explained that contemporary and historical items were presented together in order "to surprise people" or "draw attention" to them, "as a joke to make people wake up," to establish a "contrast to make people think" or to engage visitors in "looking consciously." 3

\section{Framing 'Asia' - The Asian Pavilion}

The division into Netherlands-based and foreign-based visitors of the Asian Pavilion was almost equal. Slightly more than $40 \%$ of interviewees came to the Rijksmuseum for sightseeing reasons, while $29 \%$ mentioned specific exhibits in the main building, for example the 'Night Watch', as their motivation. Although almost $80 \%$ of interviewees visited the main building of the Rijksmuseum first, only $25 \%$ could remember Asian exhibits on display in the main building. Visitors mentioned porcelain, but paintings, textiles, and weapons were also listed. Some visitors mentioned Delftware, though wondering whether Delftware was in fact 'Asian', while others identified it as Dutch-made but Asia-inspired. While a few interviewees gave more details, such as "porcelain in the dollhouse fetched from China by the Dutch East India Company", a majority of the visitors asked did not remember having seen a single Asian exhibit on display in the main building.

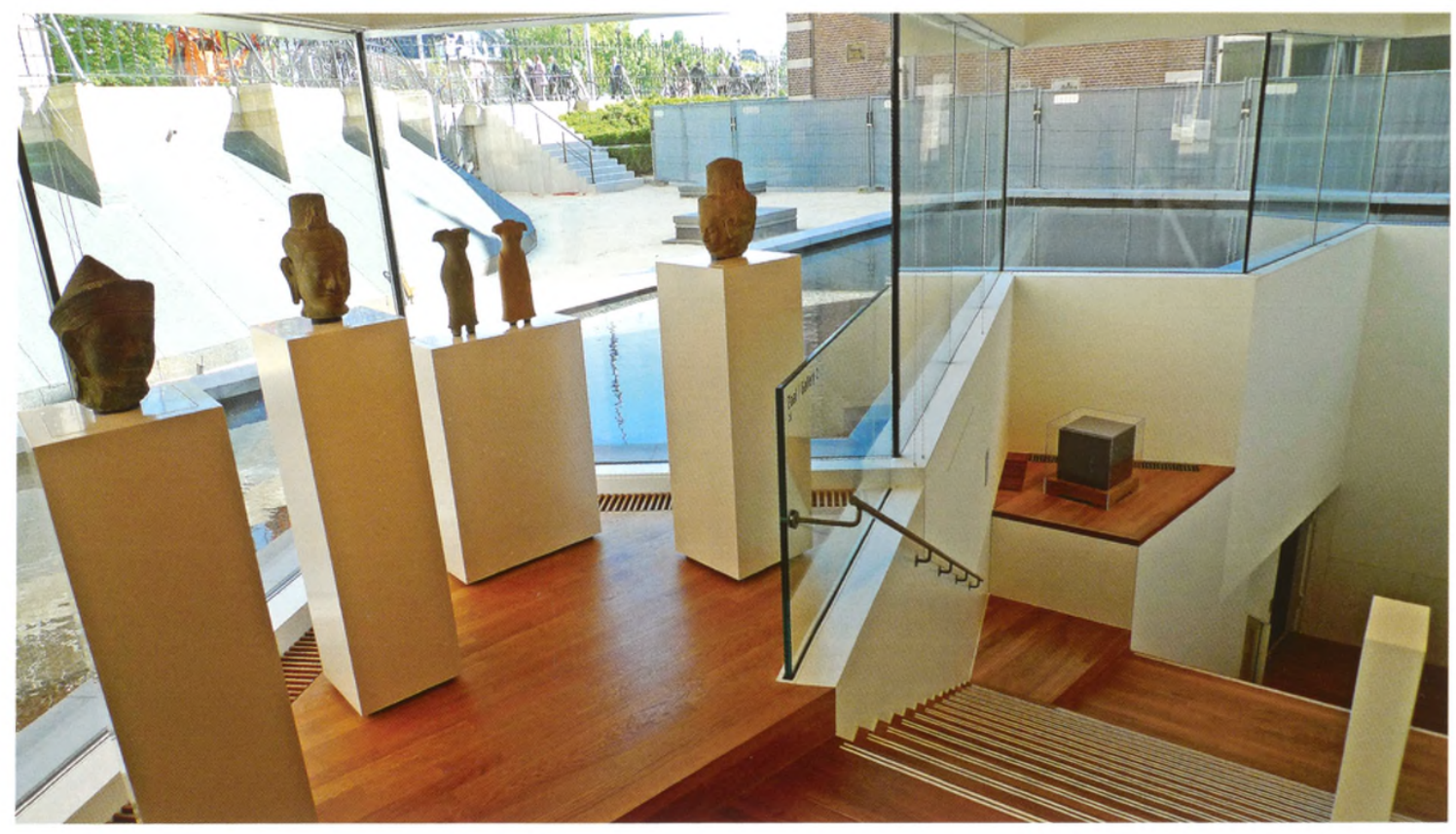


Almost half of visitors interpreted the Asian Pavilion as a supplement, complement or extension to the main building, but $22 \%$ perceived it as different from the rest of the museum and could not see a relation, while $5 \%$ interpreted the Pavilion as a confrontation or contradiction to the main building.

Some visitors related the exhibits in the Asian Pavilion to Dutch trade, while others wondered why pieces from Asian countries were the only nonEuropean exhibits on display or criticized the immediate institutional context of the Rijksmuseum: ${ }^{4}$

The Pavilion is "a curious supplement" - there is "not enough Indonesia and Japan in relation to Dutch trade, it is more under the banner of philosophy."

"It is odd, there is no explanation, no reason: Dutch art and then Asian art, no bridge, very sudden. Why Asian? Why not also African?"

"It does not fit, it is very wrong [...]. [Rijksmuseum] Volkenkunde in Leiden would have been better - this does not belong to the Rijksmuseum."

In this context, one of the interesting findings of this study is that most visitors (over 90\%) did not identify the Society of Friends of Asian Art (VVAK) as the principal owner and collector of the pieces on display in the Asian Pavilion.

Fig. 4 (left)

View of the staircase that connects the Asian Pavilion's upper and lower floors featuring Ai Weiwei, Tea Brick, Pu'er tea, wooden pedestal, h. $49.8 \mathrm{~cm}$., China, 2006, inv.nr. BK-C-2013-11, loan from the Triton Foundation, 21 maart 2013.

(c) Ai Weiwei. Photo: Dominique Provost, Brugge.
Almost $40 \%$ of visitors acknowledged that they did not know who had collected or owned the items displayed. While $20 \%$ thought that the collection was built and owned by the public (by the museum, the government, the state or the Dutch people), a further $20 \%$ assumed that the pieces were privately-held:

The collection belongs "to collectors from colonial times."
"I assume that thieves collected them and instead of being repatriated
they stayed with the government."

The pieces are "on loan from the countries where they are from."

They are "maybe from other museums, for example the Rijksmuseum Volkenkunde [sic] in Leiden."

Furthermore, while half of the visitors found the information provided sufficient, some visitors wanted additional information on the historical background and origin of the pieces on display; others more detail on the artists and craftsmen and their techniques. Some visitors also found that the "curatorial narrative could be more clearly mapped" and wanted more information on the ownership and choice of the objects collected and displayed. 
Fig. 5

Edmund de Waal, An Idea for the Journey), aluminium, perspex, porcelain and gold, h. 152 cm., 2013, inv.nr. AK-MAK-1735, loan from de Vereniging van Vrienden der Aziatische Kunst.

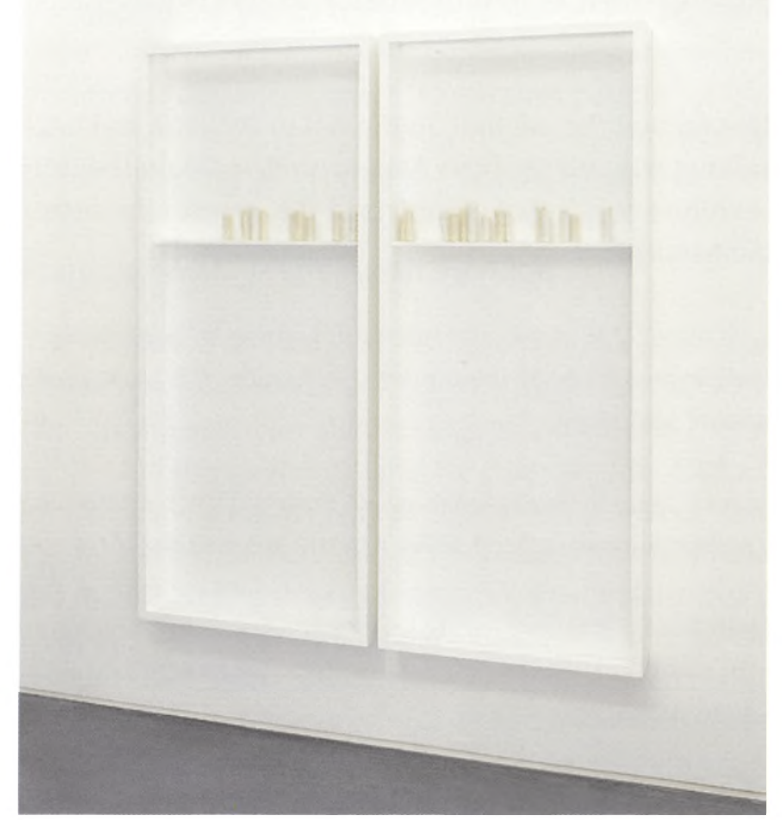

About $14 \%$ of visitors had expected exhibits from other Asian countries, for example Thailand, while about $16 \%$ of interviewees said that they had expected more paintings and (wood cut) prints, stating, for example, that the collection "is more concentrated on objects than paintings [...] in particular when I compare this section to the other part of the museum." Visitors also concluded that:

"We know that it [Asian art] consists predominantly of objects, so that's correct."

"I don't know if it is really art - the sculptures are from life and temples, daily use."

“Maybe they don't paint? What was made [in Asia], is it always in relation with religion?"

\section{Conclusion}

As findings indicate, the co-presentation of contemporary alongside historical pieces - at least as realized in the Asian Pavilion - did not encourage the visitors to engage with either.

Findings further indicate that it is unclear to many visitors how the Asian Pavilion and its collection connect with the Rijksmuseum's main building. This might have to do with the perceived lack of a continuous curatorial narrative as indicated by a majority of visitors who did not perceive or

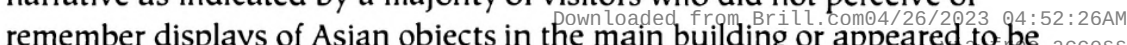


confused about the differences between European and Asian objects in this context. The definition of 'Asian' as suggested by the Pavilion's title was questioned by some visitors who had expected to see artifacts from other parts of Asia than those that were actually on display.

While a considerable amount of visitors (29\%) indicated paintings (most prominently the 'Night Watch') as main motivation for visiting the Rijksmuseum, a lack of paintings and prints in the Asian Pavilion was also mentioned by a small number of interviewees. In addition, the audio guide's selection of two Asian sculptures in the Pavilion as opposed to numerous European paintings in the tour through the main building risks to channel the perception of a painting-focused European part and an object-concentrated Asian section which in turn might negatively reinforce rather than deconstruct some problematic stereotypical views of the very nature of artistic practices in Asia.

The ownership and acquisition circumstances of the Asian Pavilion collection were unknown to most visitors. At the same time, some visitors indicated their interest in learning more about the historical and cultural background of the items on display, with a special interest in the history of the collection.

- Anna Grasskamp is post-doctoral fellow at Cluster of Excellence Asia and Europe in a Global Context, Heidelberg University. In 2013 she received a Ph.D. from the Department of Art History at Leiden University. She has published on the German Kunstkammer and is currently working on a book-length study on the display of foreign collectibles in early modern China and Europe.

- Annette Löseke specialises in museum studies, visitor and reception studies, and exhibition development. She has lectured at Humboldt University and Free University Berlin. She holds a Ph.D. in Art History from the University of Bonn. Her current research focuses on developing intercultural exhibition models. A recent article explores the chances and challenges of co-presenting contemporary and historical pieces (Engage 31 2012).

\section{Bibliography}

Annette Löseke, 'Co-presenting Past and Present: Visitor studies on the reception process', Engage 31 (2012), pp. 51-8.

\section{Notes}

* We are grateful to Mariana Francozo for integrating the study into her teaching at Leiden University. We would like to thank her, Csilla Ariese, Samuel Cardenas Meijers, Eldries Con Aguilar, Claire Earley, Sanne Koch, Flora Löw, Diana Medne, Maria Ordonez, Berber van der Oord, Diana Visser, Vivian van der Werf and Eline van den Berg for their assistance in collecting and analyzing the data.

1. Where appropriate, quotations have been translated from Dutch into English.

2. A few visitors mentioned kimonos, ceramics, jewellery, lacquer boxes, screens, and "modern art" as their favourites.

3. See findings from a previous visitor study, Löseke 2012.

4. Quotes are not representative. They were chosen to illustrate the range of answers given. 